\title{
MINIMAL LOSS RECONFIGURATION CONSIDERING RANDOM LOAD: APPLICATIONS TO REAL NETWORKS
}

\section{RECONFIGURACIÓN A MÍNIMAS PÉRDIDAS, CONSIDERANDO LA ALEATORIEDAD DE LA CARGA: APLICACIÓN A SISTEMAS REALES}

\author{
Hugo Opazo Mora ${ }^{1}$ Luis García-Santander ${ }^{1} \quad$ Enrique López Parra $^{1}$ \\ Rodrigo López González ${ }^{2} \quad$ Jorge Mendoza Baeza $^{3}$
}

Recibido el 8 de marzo de 2007, aceptado el 16 de noviembre de 2007

Received: March 8, 2007 Accepted: November 16, 2007

\begin{abstract}
RESUMEN
Este trabajo plantea la reconfiguración a mínimas pérdidas, tomando en cuenta las variaciones de carga del sistema, a través de un proceso de reconfiguración estocástico. El método de Monte Carlo es usado para considerar las variaciones naturales de la carga, utilizando una función de probabilidad normal para generar niveles aleatorios de carga en los nudos. Los resultados de este trabajo muestran la existencia de un conjunto de ramas que son frecuentemente eliminadas en el proceso de reconfiguración. Esto genera un conjunto de ramas de un árbol, las que mejor representan aleatoriedad universal de la carga. La topología obtenida la denominamos "Conjunto de Ramas Esperadas” (Expected Branch Set, EBS). La topología asociada al EBS es casi similar a la topología obtenida usando los valores de demanda promedio. Esto hace innecesario el realizar un considerable número de pruebas para encontrar la topología que mejor considera las variaciones de carga. El algoritmo propuesto fue aplicado a dos sistemas de prueba y a un sistema real de gran envergadura.
\end{abstract}

Palabras clave: Reconfiguración, sistema de distribución, EBS, minimización de pérdidas, método de Monte Carlo.

\section{ABSTRACT}

This paper approaches the minimal loss reconfiguration problem, taking into account the load variations of the systems, through a stochastic reconfiguration process. The Monte Carlo method is used to consider the natural load variation. A normal probability function is used to generate aleatory load levels in the nodes. The results of this work show the existence of a set of branches that are frequently eliminated. This generates a tree branch set that best represents the universal randomness of the load. We call it "Expected Branch Set (EBS)". The topology associated to the EBS coincides with that obtained using the average demand values. This makes it unnecessary to generate a considerable number of tests to find that topology that best considers the load variation. The proposed algorithm was applied to two test networks and to a large real network.

Keywords: Reconfiguration, distribution Networks, EBS, loss minimization, Monte Carlo method.

\section{INTRODUCTION}

Network reconfiguration is an alteration process in the topological structure of distribution feeders through changes in the on/off state of the sectional switches. During normal operating conditions, networks can be reconfigured to reduce the power losses caused by the Joule effect. This process is known as minimal loss reconfiguration problem. One of the first papers published in this field was presented by Merlin and Back [1], who developed a heuristic approach.
This solution scheme starts with a total meshed system in which all the switching elements are closed. They are then opened one by one until all the closed circuits are eliminated, and a radial system is obtained. However, the application of this method to real systems is not practical due to the significant computer effort required. This method was later modified by Shirmohammadi and Hong [2]. They reduced computing time by applying a more efficient load flow. Another research approach on minimal loss reconfiguration is proposed by Civanlar [3]. In this paper,

\footnotetext{
1 Departamento de Ingeniería Eléctrica. Universidad de Concepción. Concepción, Chile. E-mail: huopazo@udec.cl, elopez@udec.cl, luigarci@udec.cl

2 Networks research group - GRJM / ADIS. Université Paris - Sud XI. Paris, France. E-mail: rlopezg@ieee.org

3 Escuela de Ingeniería Eléctrica. Pontificia Universidad Católica de Valparaíso. Valparaíso, Chile. E-mail: jorge.mendoza@ucv.cl
} 
an analytical expression is developed in order to estimate loss reduction produced by open and close actions without altering the radiality of the system. The authors also provide some criteria to eliminate undesired switching. This kind of solution, called "branches interchange algorithm", is based solely on heuristics. Sarfi [4] present a survey in the area of distribution systems reconfiguration, ranging from the fundamental work of Merlin and Back, to the current state of art in 1993. In regards to load reduction on real-time operation considering load variability, Wagner [5] indicated that an important loss reduction was obtained through simulations in Canadian networks during a oneyear period. R. Broadwater [6] presented algorithms to reduce losses through load estimators that consider the load variability. Chen [7] showed hourly reconfiguration benefits based on short and long-term loss reduction. An optimal power flow model for minimal losses is applied by C. Brian [8]. This paper presents only results and conclusions about hourly reconfiguration for on-line power operation in an energy control center. Peponis [9], obtained loss minimization by the installation of capacitors and by network reconfiguration. They also took into account the impact of load modeling. The application method is presented in [10]. A heuristic constructive method for minimal losses reconfiguration is proposed by T. E. McDermont in [11]. In each stage, by means of a loss incremental evaluation, a new node is added that introduces minimal losses. López [12], presented an algorithm for minimal loss reconfiguration, based on the dynamic programming approach. This method is quite simple and the results are obtained in a very short computing time, so it is applicable to real big-sized systems. Therefore, it opens a way to real time reconfiguration of networks. Finally López [13] presented an application of the algorithm to on-line reconfiguration considering variability demand using daily profiles of various loads (industrial, commercial, public lighting).

One important conclusion of these previous works is that in short term and medium term the load variation is not relevant to the topological solutions e.g. independently of all possible values of demand, the total number of topologies to be considered is extremely reduced. This is because the objective function of the optimization problem shows a leveling off of the optimum zone (there is less sensibility towards the objective function regarding the load demand in this region). Consequently, we analyzed the reconfiguration problem as a probabilistic problem, assuming the existence of whatever aleatory events that could have an effect on the resulting topologies.

In this paper, the switching actions to reduce losses take into account the varying nature of loads. This is done through the use of the Monte Carlo Method Applied to
Reconfiguration (MCR): node powers are considered as a Normal Probability Function (NPF), having an "expected power" $(\mu)$ and a "standard deviation" $(\sigma)$. In this paper, the MCR is applied first to two test networks and then to a real network in order to evaluate the reconfiguration advantages considering the random load in each node. The studies are made with the model developed in [12], including demand aspects such as the models themselves ( $\mathrm{P}$, $\mathrm{Z}$ or I constant). Daily load patterns, such as those shown in [13] and [16] are used to assume average demand values and standard deviation values. Based on the preceding information, values of " $\sigma \% ", 15 \%, 30 \%$ and $50 \%$ are used in this paper. These standard deviation values amply cover the load variations of real systems.

\section{MINIMAL LOSS RECONFIGURATION}

\section{Minimal Loss Problem}

The minimal loss reconfiguration problem in distribution systems, through topological changes, can be written as follows [1-4]:

$$
\text { Minimize } \sum_{b=1}^{N r} R_{b} \cdot i_{b}^{2}
$$

Subject to:

$$
\begin{gathered}
{[A]^{T} \cdot[i]=I} \\
i \leq i_{\text {máx }} \\
V^{\min } \leq V \leq V^{\max } \\
M=N-N_{f}
\end{gathered}
$$

$\begin{array}{ll}\text { Where: } & \\ \mathrm{Rb} & : \text { Resistance of branch " } \mathrm{b} " \\ \mathrm{Ib} & : \text { Complex current in branch "b" } \\ \mathrm{i} & : \text { Branches currents vector } \\ \mathrm{i}_{\max } & : \text { Maximum branches current } \\ \mathrm{I} & : \text { Vector of node currents } \\ {[\mathrm{A}]} & : \text { Incidence matrix } \\ \mathrm{V} & : \text { Node voltage } \\ \mathrm{V}^{\min } & : \text { Minimum node voltage } \\ \mathrm{V}^{\max } & : \text { Maximum node voltage } \\ N r & : \text { Total number of branches } \\ M & : \text { Branch number of radial network } \\ N & : \text { Number of nodes } \\ N f & : \text { Number of sources }\end{array}$


Equation (2) corresponds to the balance of load currents in each node. Equation (3) corresponds to the feeder's thermal limits. Equation (4) considers voltage constraints in each node. Finally the fourth constraint (5) is the radiality restriction in a primary distribution system.

\section{Demonstrative Example}

The procedure can be described by using the small test system shown in figure 1, whose parameters are given in table 1 . Node 1 is the only source.

$$
\begin{aligned}
& \text { (1) }-\mathrm{L}_{1}-\text { - (2) } \\
& \begin{array}{lll}
1 & 1 \\
\mathbf{L}_{2} & \mathbf{L}_{3}
\end{array} \\
& \text { (3) }-\mathbf{L}_{4}--(4)--\mathbf{L}_{5}--(5)
\end{aligned}
$$

Figure 1. Test systems in Demonstrative Example.

Table 1. Test System Characteristics.

\begin{tabular}{|c|c|c|c|c|}
\hline Line & Start Node & Final Node & R(p.u.) & $\begin{array}{c}\mathrm{I}_{\mathrm{L}} \\
\text { (p.u.) }\end{array}$ \\
\hline 1 & 1 & 2 & 0.3 & 0.34 \\
\hline 2 & 1 & 3 & 0.2 & 1.00 \\
\hline 3 & 2 & 4 & 0.2 & 0.67 \\
\hline 4 & 4 & 5 & 0.1 & 1.00 \\
\hline 5 & 3 & 4 & 0.1 & -- \\
\hline
\end{tabular}

The resume results are showed in table 2 . At the beginning, we consider no connection at all, so that there are no losses. Then in the first stage, we consider connecting one node to the unique source; we have only two choice: connect 2 or 3; connection 1-2 leads to losses equal to 0.035 (p.u.), while connecting 1-3 lead to losses equal to 0.200 (p.u.). We choose to connect 1-2 (figure 2.1), and we say that selected variable is $X_{1}^{*}=2$ and the following state will be $S=2$. Similarly, in stage 2 the selected variable is $\mathrm{X}_{2} *=3$ and the next state is $\mathrm{S}=3$ (figure 2.2). In stage 3 the selected variable is $X_{3}^{*}=4$ and the next state is $S=4$ (figure 2.3). Stage 4 does not imply big changes because there is only one possible way to incorporate state 5 (figure 2.4). It is as follows: $f^{*}(5)=1.474$ (p.u.). When the state $S=5$ is incorporated in the stage 4 , a "horizontal chaining" is produced. Here a new state is not incorporated, but branch distribution is recombined. For stage 5 , the selected variable is $X_{5} *=3$ and the next state is $S=2$ which implies that branches 2-4 and 3-4 interchange on stage 6 (figure 2.5). Stage 7 does not make any changes in the topological structure (figure 2.5). Finally, branches 1-2, 1-3, 3-4, 4-5 make up the definite configuration. The loss for this configuration is 1.840 (p.u.).

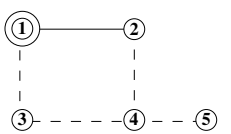

Stage 1

Figure 2.1



Stage 2

Figure 2.2

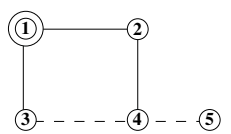

Stage 3

Figure 2.3<smiles>[C-]1CC=CO1</smiles>

Stage 4, 5

Figure 2.4

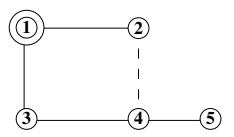

Stage 6, 7

Figure 2.5
Figure 2. Development stages of the minimal loss topology.

Table 2. Application of DP Method to the Test System.

\begin{tabular}{|c|c|c|c|c|c|}
\hline Stage & $\left(\mathrm{S}_{\mathrm{n}}, \mathrm{X}_{\mathrm{n}}\right)$ & $\mathrm{f}\left(\mathrm{S}_{\mathrm{n}}, \mathrm{X}_{\mathrm{n}}\right)$ & $\mathrm{f}_{\mathrm{n}} *(\mathrm{~S})$ & $\mathrm{X}_{\mathrm{n}} *$ & Results \\
\hline 1 & $\begin{array}{c}(1,2) \\
(1,3)\end{array}$ & $\begin{array}{c}0,035 \\
0,200\end{array}$ & 0,035 & 2 & Fig. 2.1 \\
\hline 2 & $\begin{array}{c}(1,3) \\
(2,4)\end{array}$ & $\begin{array}{c}0,200 \\
0,361\end{array}$ & 0,200 & 3 & Fig. 2.2 \\
\hline 3 & $\begin{array}{c}(2,4) \\
(3,4)\end{array}$ & $\begin{array}{c}0,361 \\
0,403\end{array}$ & 0,361 & 4 & Fig. 2.3 \\
\hline 4 & $(4,5)$ & 1,474 & 1,474 & 5 & Fig. 2.4 \\
\hline 5 & $\begin{array}{c}(1,3) \\
(4,3)\end{array}$ & $\begin{array}{c}0,200 \\
2,470\end{array}$ & 0,200 & 3 & Fig. 2.4 \\
\hline 6 & $\begin{array}{c}(2,4) \\
(3,4)\end{array}$ & $\begin{array}{c}1,735 \\
1,505\end{array}$ & 1,505 & 4 & Fig. 2.5 \\
\hline 7 & $\begin{array}{c}(1,2) \\
(4,2)\end{array}$ & $\begin{array}{c}0,035 \\
0,534\end{array}$ & 0,035 & 2 & Fig. 2.5 \\
\hline
\end{tabular}

\section{General Algorithm of Reconfiguration}

The minimal loss reconfiguration is solved by the Dynamic Programming Approach. The following algorithm describes the method [12].

i) System data: Number and rating of power substations and feeders, topology and switching possibilities of the power apparatus connected to the network.

ii) Actual operation: To evaluate the actual system conditions such as node voltage, and real and reactive losses.

iii) Graph compression: When there is a set of nodes with non-reconfigurable radial topology, an equivalent node representing the load of the subsystem is considered.

iv) Possible node connections: The process goes from each source node of the network (substation) to the final load nodes, connecting each new possible node. 
v) Losses functional evaluation: In each stage the connection of a new node is added to the tree, producing the lowest increment in losses functional.

vi) Radial load flow: To determine voltage profile, currents and losses. In this case, nodes are considered according to the load type (P, Z or I, constant).

vii) Backtracking process: The effect of the last load connection in the structure is evaluated by applying a backward process.

viii) Constraints: Verification of thermal limits in substations and feeders, voltage profiles and other constraints. If a constraint is not fulfilled, a transfer of loads between sub-stations should be made and step iv) should be performed again.

ix) Radial systems: The process goes on, until all loads are connected to the network; if not, they all go to iv).

x) Final loss evaluation: A fast radial load flow is applied to determine the network's final losses.

\section{THE MONTE CARLO RECONFIGURATION}

The Monte Carlo Method (MCM) is basically a statistical simulation that uses a random sequence of numbers to describe the statistical behavior of a variable (in this case the node demand). This work uses a NPF with characteristic statistical indexes: expected value " $\mu$ " and standard deviation " $\sigma$ ". The distribution of a normal variable is entirely determined by these two parameters. The NPF is described by equation (6), which determines a "bell shaped" curve, shown in figure 3 . The hypothesis of the MCM, as a mathematical technique, infers the search of an efficient solution instead of an accurate solution [14].

$$
\mathrm{f}(\mathrm{x})=\frac{1}{\sigma \cdot \sqrt{2 \cdot \pi}} \cdot e^{-\frac{1}{2} \cdot\left(\frac{(x-\mu)^{2}}{\sigma^{2}}\right)}
$$

Where:

$\mathrm{x}$ : Random variable

$\mu$ : Expected value of " $\mathrm{x}$ "

$\sigma$ : Standard deviation of " $\mathrm{x}$ "

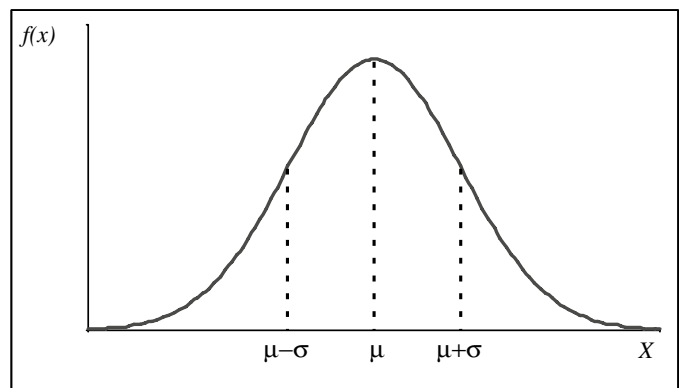

Figure 3. Probability Function with Normal Distribution.
The substations composite demands vary in time according to: industrial, commercial, residential, street lighting and mixed loads [16-19], following different patterns of behavior. The use of the NPF considers the natural composite load variations, based on the characteristics of the demand predictors and the data acquisitions systems (regarding: ranges, variance and Pearson variation coefficients). On the other hand, practice indicates that the composite demand values in a substation exhibit medium Curtosis indexes and low asymmetry coefficients of Fischer. Thus, the probabilistic values for the demand $\left(P_{n}\right.$ and $\left.Q_{n}\right)$ can be correctly represented by quasi-Mesocurtics functions i.e., distributed in a NPF [15]. Consequently, the expected value and standard deviation of node composite demands were assumed, i.e., medium loads and realistic standard deviations for the electrical systems that were studied (two test systems and one real system), according to the specific node and the study to be carried out. This permits working with two test systems shown in the literature, of which the particular stochastic behavior is unknown. Besides, the above is based on the application of our method to planning of the operation in distribution networks.

\section{ALGORITHM USED}

The algorithm developed to determine the minimal losses topology, considering the node load random variation, is made up of the following steps [12]:

1. Data Input: Network topological data and node powers are entered in the Data Base

2. Random Power Generation: Node powers are generated randomly with a normal probability distribution

3. Network Reconfiguration: The algorithm reconfiguration for minimal losses based on Modified Dynamic Programming is applied

4. Data Updating: The topological result, obtained from the reconfiguration method, is updated, storing the branches that open and close in the process

5. Number of Simulations: The quantity of reconfiguration evaluations (in this case 3000) is verified. If this is not met, it goes back to step 2

6. Final Data Processing: Data from the opened (disconnected) and closed (connected) branches are arranged, thus getting how many times each branch opened or closed. 


\section{APPLICATIONS}

\section{Method Validation}

In table 3, relevant data of both testing systems and of the real system is presented, such as: source number, node number, line number and active and reactive powers in each node. The real system includes commercial, residential, industrial and public lighting loads [12].

Table 3. Parameters of Test Systems.

\begin{tabular}{|c|c|c|c|c|c|}
\hline Name & Sources & Nodes & Lines & $\mathrm{P}(\mathrm{MW})$ & $\mathrm{Q}$ (MVAR) \\
\hline Syst. $\mathrm{N}^{\circ} 1$ & 1 & 33 & 37 & 3,7 & 2,3 \\
\hline Syst. N 2 & 3 & 26 & 45 & 57,4 & 19,8 \\
\hline $\begin{array}{c}\text { Real } \\
\text { System }\end{array}$ & 4 & 917 & 959 & 107,6 & 48,38 \\
\hline
\end{tabular}

Figure 4, shows testing System 1 . Two nodes are analyzed (node 10 and node 23). Figure 5 and figure 6 show the generated random powers. These nodes correspond to maximum, minimum and medium demand from System $\mathrm{N}^{\circ} 1$ (considering a standard deviation equal to $30 \%$ ).

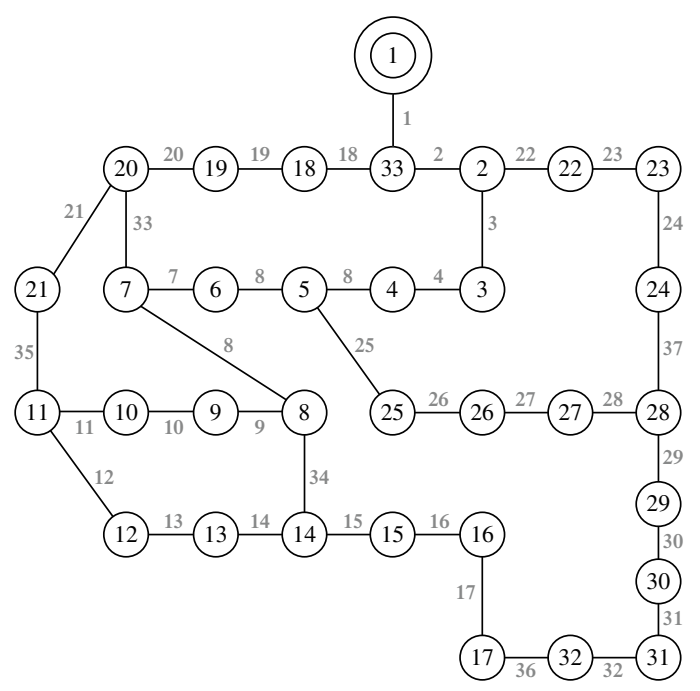

Figure 4. Testing System 1 (meshed).

Table 4, shows the expected demand values (Po), Monte Carlo expected power $(\mu)$ and Monte Carlo standard deviation $(\sigma)$, for the two nodes of System 1 (node 10 and node 23 ).
Table 4. Values of Demanded Power $\left(\sigma_{0}=30 \%\right)$.

\begin{tabular}{|c|c|c|c|}
\hline $\mathrm{N}^{\circ}$ node & Po $(\%)$ & $\mu(\%)$ & $\sigma(\%)$ \\
\hline 23 & 4,20 & 4,18 & 1,26 \\
\hline 10 & 0,45 & 0,45 & 0,13 \\
\hline
\end{tabular}

Figure 5 and figure 6, prove effectively that node powers follow a normal distribution.

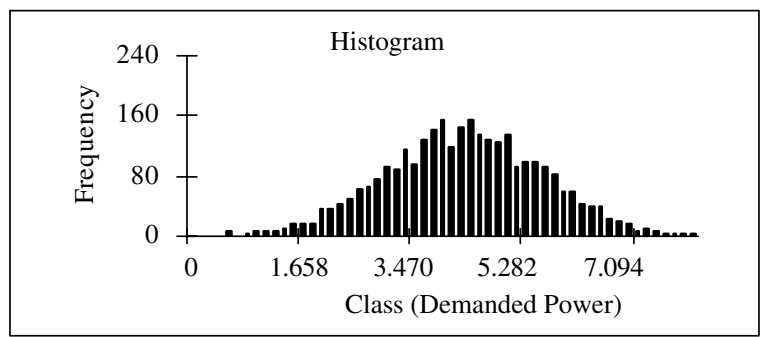

Figure 5. Node $\mathrm{N}^{\circ} 23$ Histogram. Highest demand node from System 1.

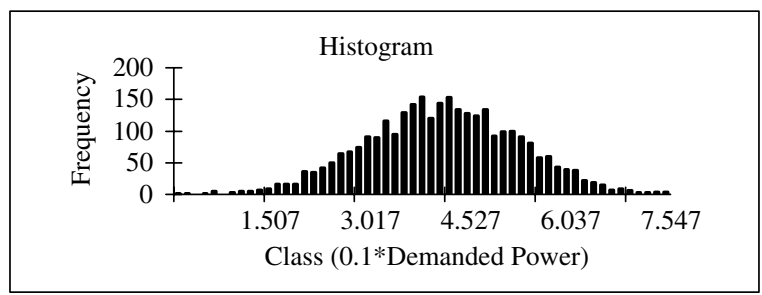

Figure 6. Node $\mathrm{N}^{\circ} 10$ Histogram Lowest demand node from System 1.

\section{Testing System 1}

When applying MCR in System 1, see figure 4, five branches must be eliminated (opened) to obtain a radial topology with minimal losses. Tables 5, 6 and 7 show the results for standard deviation of $15 \%, 30 \%$ and $50 \%$ respectively. Results show eliminated branches sequences, the number of the eliminated branch, the nodes between which the eliminated branch is connected $\left(\mathrm{N}_{\mathrm{p}}-\mathrm{N}_{\mathrm{q}}\right)$, the occurrence and the branch elimination percentage in respect to the 3.000 evaluations.

\section{Testing System 2 [20]}

The MCR is applied to System 2. In this system, 22 branches must be eliminated to obtain a radial topology at minimal losses. Tables 8, 9 and 10 show the resumed results for a standard deviation of $15 \%, 30 \%$ and $50 \%$ respectively. Results show: the eliminated branch sequences, the occurrence, and branch elimination percentage in regards to the 3.000 evaluations. 


\section{Real System [21]}

MCR was applied to determine the minimal losses topologies that result in the real system, taking into consideration the random values of the node load. For this system, 43 branches in each reconfiguration step must be opened to maintain radial topology at minimal losses. Tables 11,12 and 13 present the resumed results obtained for a standard deviation of $15 \%, 30 \%$ and $50 \%$ respectively. These tables show a summary of the results obtained for different values of deviation. These tables show a change in the opening and the percentage of eliminated branches when applying the reconfiguration, starting from sequence 43 .

\section{Topologies comparison in real system}

Table 14, shows a comparison between the losses obtained when reconfiguring the real system, applying the method proposed in [12], and the losses obtained when using the EBS topology at different load levels $(75 \%, 100 \%$ and $125 \%$ ).

Table 5. Load Variation of $15 \%$ (System 1).

\begin{tabular}{|c|c|c|c|c|}
\hline Sequence & $\begin{array}{c}\text { Branch } \\
\mathrm{N}^{\circ}\end{array}$ & $\mathrm{Np}-\mathrm{Nq}$ & $\begin{array}{c}\mathrm{N}^{\circ} \text { of times } \\
\text { that opens }\end{array}$ & $\begin{array}{c}\% \\
\text { opening }\end{array}$ \\
\hline $\mathbf{1}$ & $\mathbf{9}$ & $\mathbf{8 - 9}$ & $\mathbf{2 9 9 9}$ & $\mathbf{9 9 , 9 7}$ \\
\hline $\mathbf{2}$ & $\mathbf{1 4}$ & $\mathbf{1 3 - 1 4}$ & $\mathbf{2 9 9 8}$ & $\mathbf{9 9 , 9 3}$ \\
\hline $\mathbf{3}$ & $\mathbf{7}$ & $\mathbf{6 - 7}$ & $\mathbf{2 9 4 9}$ & $\mathbf{9 8 , 3 0}$ \\
\hline $\mathbf{4}$ & $\mathbf{3 7}$ & $\mathbf{2 4 - \mathbf { 2 8 }}$ & $\mathbf{2 6 2 7}$ & $\mathbf{8 7 , 5 7}$ \\
\hline $\mathbf{5}$ & $\mathbf{3 2}$ & $\mathbf{3 1 - 3 2}$ & $\mathbf{2 4 2 5}$ & $\mathbf{8 0 , 8 3}$ \\
\hline 6 & 31 & $30-31$ & 436 & 14,53 \\
\hline 7 & 28 & $27-28$ & 373 & 12,43 \\
\hline 8 & 30 & $29-30$ & 139 & 4,63 \\
\hline 9 & 33 & $7-20$ & 51 & 1,70 \\
\hline 10 & 34 & $8-14$ & 2 & 0,07 \\
\hline 11 & 11 & $10-11$ & 1 & 0,03 \\
\hline
\end{tabular}

Table 6. Load Variation of 30\% (System 1).

\begin{tabular}{|c|c|c|c|c|}
\hline Sequence & $\begin{array}{c}\mathrm{N}^{\circ} \text { of } \\
\text { Branch }\end{array}$ & $\mathrm{Np}-\mathrm{Nq}$ & $\begin{array}{c}\mathrm{N}^{\circ} \text { of times } \\
\text { that opens }\end{array}$ & $\begin{array}{c}\% \\
\text { Opening }\end{array}$ \\
\hline $\mathbf{1}$ & $\mathbf{9}$ & $\mathbf{8 - 9}$ & $\mathbf{2 8 1 8}$ & $\mathbf{9 3 , 9 3}$ \\
\hline $\mathbf{2}$ & $\mathbf{1 4}$ & $\mathbf{1 3 - 1 4}$ & $\mathbf{2 8 0 8}$ & $\mathbf{9 3 , 6 0}$ \\
\hline $\mathbf{3}$ & $\mathbf{7}$ & $\mathbf{6 - 7}$ & $\mathbf{2 3 8 8}$ & $\mathbf{7 9 , 6 0}$ \\
\hline $\mathbf{4}$ & $\mathbf{3 7}$ & $\mathbf{2 4 - \mathbf { 2 8 }}$ & $\mathbf{2 2 1 5}$ & $\mathbf{7 3 , 8 3}$ \\
\hline $\mathbf{5}$ & $\mathbf{3 2}$ & $\mathbf{3 1 - 3 2}$ & $\mathbf{1 5 1 5}$ & $\mathbf{5 0 , 5 0}$ \\
\hline 6 & 30 & $29-30$ & 889 & 29,63 \\
\hline-- & -- & -- & -- & -- \\
\hline 17 & 6 & $5-6$ & 3 & 0,03 \\
\hline 18 & 26 & $25-26$ & 1 & 0,03 \\
\hline
\end{tabular}

Table 7. Load Variation of 50\% (System 1).

\begin{tabular}{|c|c|c|c|c|}
\hline Sequence & $\begin{array}{c}\mathrm{N}^{\circ} \text { of } \\
\text { Branch }\end{array}$ & $\mathrm{Np}-\mathrm{Nq}$ & $\begin{array}{c}\mathrm{N}^{\circ} \text { of times } \\
\text { that opens }\end{array}$ & $\begin{array}{c}\% \\
\text { Opening }\end{array}$ \\
\hline $\mathbf{1}$ & $\mathbf{9}$ & $\mathbf{8 - 9}$ & $\mathbf{2 7 7 9}$ & $\mathbf{9 2 , 6 3}$ \\
\hline $\mathbf{2}$ & $\mathbf{1 4}$ & $\mathbf{1 3 - 1 4}$ & $\mathbf{2 7 6 8}$ & $\mathbf{9 2 , 2 7}$ \\
\hline $\mathbf{3}$ & $\mathbf{7}$ & $\mathbf{6 - 7}$ & $\mathbf{2 3 5 6}$ & $\mathbf{7 8 , 5 3}$ \\
\hline $\mathbf{4}$ & $\mathbf{3 7}$ & $\mathbf{2 4 - \mathbf { 2 8 }}$ & $\mathbf{2 1 6 9}$ & $\mathbf{7 2 , 3 0}$ \\
\hline $\mathbf{5}$ & $\mathbf{3 2}$ & $\mathbf{3 1 - 3 2}$ & $\mathbf{1 3 9 1}$ & $\mathbf{4 6 , 3 7}$ \\
\hline 6 & 30 & $29-30$ & 875 & 29,17 \\
\hline-- & -- & -- & -- & -- \\
\hline 23 & 10 & $9-10$ & 2 & 0,07 \\
\hline 24 & 15 & $14-15$ & 1 & 0,03 \\
\hline
\end{tabular}

Table 8. Load Variation of 15\% (System 2).

\begin{tabular}{|c|c|c|}
\hline Sequence & $\mathrm{N}^{\circ}$ of Openings & \% Opening \\
\hline $\mathbf{1 ~ t o} \mathbf{1 5}$ & $\mathbf{3 0 0 0}$ & $\mathbf{1 0 0 , 0}$ \\
\hline-- & -- & -- \\
\hline $\mathbf{2 2}$ & $\mathbf{2 4 9 2}$ & $\mathbf{8 3 , 0 7}$ \\
\hline 23 & 508 & 16,93 \\
\hline-- & -- & -- \\
\hline 30 & 10 & 0,33 \\
\hline
\end{tabular}

Table 9. Load Variation of 30\% (System 2).

\begin{tabular}{|c|c|c|}
\hline Sequence & $\mathrm{N}^{\circ}$ of Openings & \% Opening \\
\hline $\mathbf{1}$ to $\mathbf{1 2}$ & $\mathbf{3 0 0 0}$ & $\mathbf{1 0 0 , 0}$ \\
\hline-- & -- & -- \\
\hline $\mathbf{2 2}$ & $\mathbf{2 3 5 0}$ & $\mathbf{7 8 , 3 3}$ \\
\hline 23 & 650 & 21,67 \\
\hline-- & -- & -- \\
\hline 33 & 19 & 0,63 \\
\hline
\end{tabular}

Table 10. Load Variation of 50\% (System 2).

\begin{tabular}{|c|r|r|}
\hline Sequence & N $^{\circ}$ of Openings & \% Opening \\
\hline $\mathbf{1}$ to $\mathbf{8}$ & $\mathbf{3 0 0 0}$ & $\mathbf{1 0 0 , 0}$ \\
\hline-- & -- & -- \\
\hline $\mathbf{2 2}$ & $\mathbf{2 3 4 5}$ & $\mathbf{7 8 , 1 7}$ \\
\hline 23 & 655 & 21,83 \\
\hline-- & -- & -- \\
\hline 35 & 4 & 0,13 \\
\hline
\end{tabular}

Table 11. Load Variation of 15\% (Real System).

\begin{tabular}{|c|r|r|}
\hline Sequence & N $^{\circ}$ of Openings & \% Opening \\
\hline $\mathbf{1 ~ t o ~ 3 1}$ & $\mathbf{3 0 0 0}$ & $\mathbf{1 0 0 , 0}$ \\
\hline $\mathbf{3 2}$ & $\mathbf{2 9 9 7}$ & $\mathbf{9 9 , 9 0}$ \\
\hline-- & -- & -- \\
\hline $\mathbf{4 3}$ & $\mathbf{2 8 1 2}$ & $\mathbf{9 3 , 7 3}$ \\
\hline 44 & 178 & 5,93 \\
\hline-- & -- & -- \\
\hline 58 & 3 & 0,10 \\
\hline
\end{tabular}


Table 12. Load Variation of 30\% (Real System).

\begin{tabular}{|c|c|c|}
\hline Sequence & N $^{\circ}$ of Openings & \% Opening \\
\hline $\mathbf{1}$ to 22 & $\mathbf{3 0 0 0}$ & $\mathbf{1 0 0 , 0}$ \\
\hline $\mathbf{2 3}$ & $\mathbf{2 9 9 9}$ & $\mathbf{9 9 , 9 7}$ \\
\hline-- & -- & -- \\
\hline $\mathbf{4 3}$ & $\mathbf{2 7 7 8}$ & $\mathbf{9 2 , 6 0}$ \\
\hline 44 & 211 & 7,03 \\
\hline-- & -- & -- \\
\hline 66 & 1 & 0,03 \\
\hline
\end{tabular}

Table 13. Load Variation of 50\% (Real System).

\begin{tabular}{|c|c|c|}
\hline Sequence & N $^{\circ}$ of Openings & \% Opening \\
\hline $\mathbf{1}$ to $\mathbf{1 0}$ & $\mathbf{3 0 0 0}$ & $\mathbf{1 0 0 , 0}$ \\
\hline $\mathbf{1 1}$ & $\mathbf{2 9 9 9}$ & $\mathbf{9 9 , 9 7}$ \\
\hline-- & -- & -- \\
\hline $\mathbf{4 3}$ & $\mathbf{2 7 6 3}$ & $\mathbf{9 2 , 1 0}$ \\
\hline 44 & 232 & 7,73 \\
\hline-- & -- & -- \\
\hline 78 & 1 & 0,03 \\
\hline
\end{tabular}

Table 14. Loss Level Comparison.

\begin{tabular}{|c|c|c|c|c|}
\hline Case & $\begin{array}{c}\text { Demand } \\
(\%)\end{array}$ & $\begin{array}{c}\text { MW Loss } \\
\text { Ref. [12] } \\
\text { topology }\end{array}$ & $\begin{array}{c}\text { MW Loss } \\
\text { EBS } \\
\text { topology }\end{array}$ & $\begin{array}{c}\Delta(\%) \\
(\mathrm{E}-3)\end{array}$ \\
\hline 1 & 75 & 2,8385 & 2,8387 & 7,045 \\
\hline 2 & 100 & 2,9192 & 2,9194 & 6,851 \\
\hline 3 & 125 & 2,9987 & 2,9990 & 10,004 \\
\hline
\end{tabular}

\section{RESULTS ANALYSIS}

Results obtained for System 1 (tables 5, 6 and 7) show that a topology can be considered as the most often repeated when taking into account random load nodes with various standard deviations. Such an "EBS topology" is obtained by opening five branches to maintain radial topology. For System 2, the same results can be observed: an "EBS topology" is obtained eliminating 22 branches (Tables 8, 9 and 10). However, it must be mentioned concerning both testing systems that two relevant facts occur when standard deviation increases $(15 \%, 30 \%$ and $50 \%)$ :

- Branch elimination percentage decreases $(80.83 \%$, $50.50 \%$ and $46.37 \%$, for Sequence 5 in System 1, Tables 5, 6 and 7).

- An increase in the quantity of eliminated or opened branches is appreciated $(11,18$ and 24 branches are eliminated in System 1, Tables 5, 6 and 7).

For the real system, 43 branches must be eliminated to obtain radial topology at minimal losses. Tables 11, 12 and 13 show the different eliminated branches and their occurrence. It can be observed that for the last eliminated branch (sequence 43) there exists an occurrence of $93.73 \%$, $92.60 \%$ and $92.10 \%$ for a standard deviation of $15 \%, 30 \%$ and $50 \%$, respectively (Table 11, 12 and 13). The opening branch occurrence from sequence 43 falls suddenly to $5.93 \%, 7.03 \%$ and $7.73 \%$ for a standard deviation of $15 \%$, $30 \%$ and $50 \%$. Moreover, similarly to testing systems, an increase of the standard deviation produces a decrease of the opening occurrence of the eliminated branches and, on the other hand, it produces an increase in the number of open branches.

Table 14, shows loss levels when a reconfiguration is applied to a real system (using the methodology presented in [12]), taking into account different load levels of the system $(75 \%, 100 \%$ and $125 \%)$. Table 12 , also shows the results obtained when applying only one radial load flow to determine the losses with the "EBS topology", taking into account the different load levels mentioned before. When reconfiguring the real network with different load levels and losses obtained when using the "EBS topology", there are very small differences between power loss results (6.851E-5\% in case 2$)$.

\section{ACKNOWLEDGEMENTS}

The authors would like to thank the Planning Ministry (MIDEPLAN) and the National Commission for the investigation, science and technology (CONICYT) of the Government of Chile, for their support in this research. In particular for the scholarship "Beca Presidente de la República" and for FONDECYT project N 11070019. The authors also acknowledge support from Pontificia Universidad Católica de Valparaíso project DI- 204.73/2007 and Dirección de Investigación de la Universidad de Concepción project DIUC No 207.092.048-1.0.

\section{CONCLUSIONS}

This paper presents a method for probabilistic minimal loss reconfiguration in electrical distribution systems considering random node loads. The loads are considered with a normal probability function, an expected value $(\mu)$, and standard deviations $(\sigma)$ provided by both our own authors' experiences, and also other authors' experiences. In each system analyzed, 3000 reconfiguration evaluations were performed with the purpose of finding in each case an Expected Branch Set (EBS). This expected branch set or "EBS topologies" is what best represents the aleatory behavior of the demand of the system. 
In practice only this EBS topology must be evaluated to consider random load. Results obtained when analyzing the real system show that the highest frequency EBS topology gives loss levels that are very close to those optimal losses obtained by the Monte Carlo reconfiguration process, taking into account all the random load levels. Therefore, the EBS topology turns out to be a useful tool in the planning and operation phases of distribution systems.

On the other hand, in all the studied cases, tests and real systems, it was found that the increase of the node power standard deviation (load variation increase) causes a decrease in the frequency of eliminated branches. Consequently, an increase in the number of eliminated branches is observed.

Finally, the results obtained in this paper are consequent with the heuristic results presented in [13], where the on-line hourly load variation is considered.

\section{REFERENCES}

[1] A. Merlin and G. Back. "Search for MinimumLoss Operational Spanning Tree Configuration for an Urban Power Distribution System”. Procc. of the Fifth Power System Conference (PSCC). Cambridge UK, pp. 1-18. 1975.

[2] D. Shirmohammadi and H. W. Hong. "Reconfiguration of Electric Distribution Networks for Resistive Line Losses Reduction". IEEE Trans. PWRD. Vol. 4 Nº 2, pp. 1492-1498. 1989.

[3] S. Civanlar, J.Grainger, H. Yin and S. Lee. "Distribution Feeder Reconfiguration for Loss Reduction”. IEEE Trans. on PWRD. Vol. 3, pp. 1217-1223, 1988.

[4] R. Sarfi, M. Salama and A. Chikhani. "A survey of the state of the art in distribution system reconfiguration for system loss reduction". Electric Power Systems Research, pp. 61-70, 1994.

[5] T. Wagner, A. Chikhani and R. Hackman. "Feeder Reconfiguration for Loss Reduction: An Application of Distribution Automation". IEEE Trans. on PWRD. Vol. $6 \mathrm{~N}^{\circ}$ 4, pp. 1922-1933. 1991.

[6] R. Broadwater, A. Khan, H. Shalan and R. Lee. "Time varying Load Analysis to Reduce Distribution Losses Though Reconfiguration". IEEE Trans. on Power Delivery. Vol. $8 \mathrm{~N}^{\circ} 1$, pp. 294-300. 1993.
[7] C. S. Chen and M. Y. Cho. "Energy Loss Reduction By Critical Switches". IEEE Transactions on Power Delivery. Vol. 8 Nº 3, pp. 1246-1253. 1993.

[8] Brian C. Shin. "Development of the Loss Minimization Function for Real Time Power System Operations: A New Tool". IEEE Trans. on Power Systems. Vol. $9 \mathrm{~N}^{\circ}$ 4, pp. 2028-2034. 1994.

[9] G. Peponis, M. Papadopoulos and N. Hatziargyriou. "Optimal Operation of Distribution Networks". IEEE Transactions on Power Systems. Vol. 11 No 1, pp. 59-67. 1996.

[10] G. Peponis, M. Papadopoulos and N. Hatziargyriou. "Optimal Operation of Distribution Networks". IEEE Transactions on Power Systems. Vol. 11 No 1, pp. 59-67. 1996.

[11] T. McDermott, I. Drezga and R. Broadwatwer. "A Heuristic Nonlinear Constructive Method for Distribution System Reconfiguration”. IEEE Transactions on Power Systems. Vol. $14 \mathrm{~N}^{\mathrm{o}} 2$, pp. 478-483. 1999.

[12] E. López, H. Opazo, L. García and M. Poloujadoff. "Minimal Loss Reconfiguration Based on Dynamic Programming Approach: Application to Real Systems". Electric Power Components and Systems. Vol.30 N 7, pp. 693-704. July 2002.

[13] E. López, H. Opazo, L. García and P. Bastard. "On-Line reconfiguration considering variability demand: Applications to real networks". IEEE Transactions on Power Systems. Vol. $19 \mathrm{~N}^{\mathrm{o}}$ 1, pp. 549-553. 2004.

[14] James N. Siddall. "Analytical Decision-Making in Engineering Design”. Ed. Prentice Hall. 1972.

[15] H. Lee Willis. "Spatial Electric Load Forecasting". Ed. Marcel Dekker Inc. Second Edition. August 2002.

[16] A. L. Shenkman. "Energy Loss Computation by using Statistical Techniques". IEEE Transactions on Power Delivery. Vol. 5 N$^{\circ}$ 1, pp. 254, 258. 1990.

[17] A. Capasso, W. Grattiery, R. Lamedica and A. Prudenzi. "A Bottom-up Approach to Residential Load Modeling". IEEE Transactions on Power Systems. Vol. 9 No $^{\circ}$, pp. 957, 963. 1994. 
[18] R. Lamedica, A. Prudenzi, M. Sforna, M. Caciotta and V.O. Cencellli. "A Neural Network Based Technique for Short-Term Forecasting of Anomalous Periods". IEEE Transactions on Power Systems. Vol. 11 No 4, pp. 1749, 1756. 1996.

[19] J. A. Jardini, C.M.V. Tahan, M.R. Gouvea, S.U. Ahn and F.M. Figueiredo. "Daily Load Profiles for Residential, Commercial and Industrial Low Voltage Consumers". IEEE Transactions on Power Delivery. Vol. $15 \mathrm{~N}^{\mathrm{o}}$ 1, pp. 375, 380. 2000.
[20] C. Pinilla. "Reconfiguración de sistemas eléctricos vía programación cuadrática”. Tesis para optar al título de ingeniero civil eléctrico. Universidad de Concepción. Concepción, Chile. Enero 2000.

[21] E. J. Molina de la Fuente. "Reconfiguración de redes de distribución primarias con cargas aleatorias". Tesis para optar al título de ingeniero civil eléctrico. Universidad de Concepción. Concepción, Chile. Diciembre 2005. 